\title{
Blount disease
}

INSERM

\section{Source}

INSERM. (1999). Orphanet: an online rare disease and orphan drug data base. Blount disease. ORPHA:2768

Blount disease is characterized by disturbed growth of the inner portion of the upper tibial extremity, progressively leading to bowlegged deformity with bone angulation just below the knee (tibia varus). In $60 \%$ of cases, the condition affects both legs. 